\title{
Letting Tourette's be?
}

\section{Jo Bervoets*(1), Diana Beljaars (2), Hanne De Jaegher $(3,4,5)$}

*Corresponding author: joberv@gmail.com

(1) NeuroEpigenEthics project, Philosophy Department, University of Antwerp

(2) Department of Geography, Swansea University

(3) IAS-Research Centre for Life, Mind, and Society, University of Basque Country

(4) Department of Psychology, University of Sussex

(5) Peter Wall Institute for Advanced Studies, University of British Columbia

\section{Abstract:}

Tourette Syndrome is almost exclusively seen through the lens of disruptive tics. The most relevant clinical question seems to be: how to combat tics? In line with emerging calls from those diagnosed, we argue for a more positive approach focused on the Tourettic person, rather than on disruptions flowing from tics. This change of focus is ethically motivated but has important theoretical implications. As an exercise in 'letting be' (i.e. of finding out what something is on its own terms, through sensitively interacting with it), it brings out the basic relationalities of Tourette's with both the non-human and the social environment. Echoing Tourettic lived experience, disruptive tics then emerge as the tips of icebergs consisting of spontaneous, even playful, interactions with the environment. A more nuanced view emerges in which problems experienced by those diagnosed are no longer located in individual brains but require comprehensive study of how tics situationally develop. Listening attentively to lived experience reports leads to a dramatic shift away from the classical lack of inhibition' model, to reveal a constant pressure to inhibit actions that one feels strongly and spontaneously compelled to do. This inhibition is dependent on what is signaled as disruptive by others and is therefore suppressed for their sake. The Tourettic person's distress or felt impairment seems more tied to an onlooker's focus on their tics, than on the severity and frequency of their tics. We conclude that 'letting be' is an attitude towards Tourette's that is worth considering, both clinically and theoretically. In fact, we believe that the overall good prognosis as to felt impairment correlates with finding trusted environments where one is 'let be' (without being 'let go of') instead of living under constant scrutiny.

\section{Keywords:}

Tourette's, neurodiversity, enactivism, letting be, lived experience 


\section{Introduction:}

The title of this paper is deliberately provocative. It is not meant as a denial of the very real problems encountered by Tourettic individuals. It is meant as an invitation to work towards a more nuanced view of Tourette's in clinical practice and theory more broadly. Tourette Syndrome is currently almost exclusively seen through a lens of disruptive tics. The only relevant question then seems to be: how to cure tics? Inspired by the emerging calls from those so diagnosed, we argue for a more positive approach focused on the Tourettic experience rather than only on disruptions flowing from tics. This allows to align research into Tourette's ${ }^{1}$ with the ethical as well as theoretical insights flowing from a neurodiversity paradigm, mostly worked out until now for autism (Bervoets and Hens 2020). As we demonstrate, such alignment opens up room to incorporate recent empirical insights including lived experience reports from Tourettic self-advocates. It results in a view that is not only ethically superior but allows for a clinical approach with firm roots in contemporary enactive philosophy (see the Productions and Erasures section below).

We proceed as follows. First, we summarize the state of the art epidemiological research into Tourette Syndrome. Next, we show how a pathological view of Tourette's along the lines of the current status quo of a brain deficit, causing a 'lack of inhibition', runs into unresolvable tensions. We then elaborate how recent trends in enactive philosophy allow formulating a more nuanced and positive view of Tourette's as a neurodiverse way of having a surplus of sensitivity in relation to one's non-human and social environment. Finally, we explain how 'letting Tourette's be' is an ethical imperative bringing a new dynamic to the theory and practice of improving lives of Tourettic people.

\section{Tourette Syndrome: facts}

The DSM-5 (American Psychiatric Association 2013) characterizes Tourette Syndrome as multiple motor tics and at least one phonic tic, with an onset before 18 years of age. Common examples of motor tics include eye-blinking and head-nodding, and examples of phonic tics include sniffing and throat-scraping. A recent population study puts prevalence at around $1 \%$ of the general population (Robertson and Eapen 2014). More often than not tics are knee jerk-like behaviors resembling 'normal' behaviors but which are more violent, more frequent and surprising. Ticcing is also not a stable trait of diagnosed people, as both the frequency and type of tic varies with environmental factors that are induced by, for instance, different everyday activities and spaces and their associated sensory load (Beljaars 2020; forthcoming). Also, the timing of diagnosis and prognosis vary extensively. Whereas in most cases onset is estimated between 4 and 6 years of age, a diagnosis can follow much later or not at all, for instance, because it is not sought (Kim et al. 2019). In most cases, the prognosis of symptoms tends to be favourable with a remission and a reduction in felt impairment in young adulthood (Groth et al. 2019).

\footnotetext{
${ }^{1}$ We use the terms 'Tourette's' and 'Tourettic people' when arguing for a more nuanced understanding away from purely pathological terms such as Syndrome or Disorder. Whilst syndrome is a less negative term than disorder, both stress the qualification 'Tourette's' as, primarily, a bad thing. This is also in line with preferences as voiced in the autism debate by those diagnosed (Kenny et al. 2016).
} 
The phenotype, as it is currently understood, is much more heterogeneous than has been commonly assumed. This is also evident from the fact that $90 \%$ of people with the Tourette Syndrome diagnosis also have one or more 'comorbid' diagnoses; Obsessive Compulsive Disorder (OCD), Attention Deficit Hyperactivity Disorder (ADHD) and autism, to name the main ones (Robertson and Eapen 2014). Suggestions have also been made for a TS/OCD spectrum, for instance by Robertson and Eapen (2014); suggestions which find support in genetic (Qi et al. 2019), behavioral (Gagné 2019) and neurological (Bhikram et al. 2020) research. Flnally, whilst uttering obscene words (coprolalia) is relatively rare, the tendency towards exhibiting 'non-obscene socially inappropriate' behavior is well documented (Eddy and Cavanna 2013) impacting social relations and Quality of Life (Cox et al. 2019).

A turn towards understanding Tourette Syndrome etiology as neurological took place after the rejection of a psychogenic approach based on psychoanalysis in the 1970's (Kushner 1999). This fundamental shift was catalyzed by a coalition between doctors and parents, among others, to remove the stigma of concepts such as 'refrigerator mothers', and against placing blame on child rearing (Ibid.). The exclusively neuroscientific focus on tics has led to conceptualizing Tourette's as a 'deficit' in the neurological structure, particularly in the basal ganglia, itself leading to a 'lack of inhibition' (Schroeder 2005).

Despite consensus on a biomedical origin of Tourette Syndrome, debates continue about underlying pathophysiological mechanisms (Singer and Augustine 2019) and to its genetic predisposition (Pagliaroli 2016). Finally, although a shift toward a purely neurological basis was made based on initial successes with pharmacological treatments (Kushner 1999), the current treatment gold standard in the US is cognitive behavioral therapy (Pringsheim et al. 2019).

\section{Tourette's: tensions}

The only thorough philosophical and ethical analysis of Tourette Syndrome was offered by Timothy Schroeder in his Moral Responsibility and Tourette Syndrome (2005). He argues that locating the origin of problematic tics squarely in the brain creates immediate grounds to excuse the person diagnosed based on their lack of inhibition caused by a neurological deficit and therefore outside their control. Tackling this putative deficit creates the promise of curing the individual of their Tourette Syndrome. Exculpation and explanation then are the twin virtues of a neuroscientific 'deficit' approach. Such a neuroscientific view has clear benefits with respect to earlier psychogenic views (Kushner 1999), but it has not yet been positively validated (Singer and Augustine 2019). Moreover, it is unable to integrate other insights in the empirical and scholarly literature. We provide an overview of such remaining tensions.

A first tension surfaces in considering the phenomenology of Tourette's. Lived experience reports emphasize the importance of context on tics: how they surface as inappropriate in a given social environment (Eddy and Cavanna 2013). Another common element in lived experience reports is the element of compulsion: how tics are felt as response to an "urge" which demands being acted on despite one's better judgement (Specht et al. 2013). The analogy that is often used is that of an urge to scratch when one feels an itch. Conditions of stress negatively affect how acutely such a compulsion is felt as well as the threshold at 
which one feels one has to give in (Specht et al. 2013). Context not only influences the content of tics but also their frequency and intensity. Tic frequency and intensity changes from minute to minute as well as with longer periodical fluctuations, and this waxing and waning seems related to how stressful the environment is (Silva et al. 1995).

These elements of context and compulsion point to a socio-spatial situatedness of ticcing which is difficult to reconcile with a pure 'deficit within the brain' assumption, as both imply an entanglement with environmental factors. Socio-spatial situatedness of tics has been studied in depth via a qualitative study on how Tourettic perception and environment are entangled (Beljaars 2020; forthcoming). Based on interviews, participant observations and mobile eye tracking, it is found that central to the Tourettic experience is feeling compelled to engage actively with one's surroundings in order to touch or rearrange them in specific ways to make them feel just-right (Leckman et al. 1993). Not giving in leads to urges and inhibiting them leads to an ever greater awareness of the element that is not-just-right and mounting tensions that ultimately become unbearable (Bliss 1980, Seligman and Hilkevich 1992). Tics can thus be immediately related to one's bodily environment.

The second element of tension is that a brain deficit view turns a behavioral diagnosis into a categorical division within humanity based on a putative and purely biological difference between humans. Such an assumption of a natural kind underlying psychiatric kinds is now generally contested (Hyman 2021). It can carry over into stigmatization and mental health problems of those diagnosed. Indeed, several studies (Haslam and Kvaale 2015, Lebowitz and Apelbaum 2019) have found that purely biomedical views of mental illness essentialize the mental disorder and thereby lead to a dehumanization of those diagnosed. Such results are also found in the specific case of Tourette Syndrome (Malli et al. 2016). Essentialization of psychopathology as static biological categories leads us "[t]o adopt the objective attitude to another human being (..) to see him, perhaps, as an object of social policy, as a subject for what, in a wide range of sense, might be called treatment, as something certainly to be taken account, perhaps precautionary account, of; to be managed or handled or cured or trained" (Strawson 2008/1962: p. 9). Such "[a] sustained objectivity of inter-personal attitudes, and the human isolation which that would entail" (ibid.:, p. 11) are ethically highly problematic. As Bervoets and Hens (2020) point out in the case of autism, essentializing into a brain deficit creates the grounds for potential injustice to people diagnosed with a mental 'condition'.

Doing justice to the phenomenology of Tourette's (Curtis-Wendlandt and Reynolds 2021) then requires valorizing the differential and situational ability evident in the Tourettic lived experience of counteracting their urges. In fact, looking at the entanglement of individual and environmental factors is not only needed to account for context and compulsion within the Tourettic lived experience, it also situates Tourette's as potentially flowing from basic human sensitivities that happen to be expressed more extremely. The latter is in line with Tourettic individuals who are trying to relate their experience to itches and other elements of common human experience (cf. Seligman and Hilkevich 1992). Seeing mental disorders as extreme expressions of basic human tendencies reduces stigmatization (Schomerus et al. 2013). To develop this more nuanced view of Tourette's in which it is positively seen as a neurodiverse way of being, characterized by a 'surplus of sensitivity' in relation to one's non-human and social environment we turn to enactive philosophy. 


\section{Productions and Erasures}

Despite the twin virtues of exculpation and explanation afforded by the neurological deficit model over earlier psychogenic models Tourette Syndrome continues to be produced ${ }^{2}$ only as a pathological problem that is reduced to observable tics.. As Hollenbeck (2003, np) puts it from a Tourettic perspective: "Tourette's (..) is largely a disease of the onlooker. When I tic I am usually not the problem. You are." Relying exclusively on the positivist methodology of quantifying tics that are denoted by objective - often non-Tourettic - raters produces Tourette Syndrome as a disease and erases the lived experience of Tourettic people, or at least reduces experience reports to secondary, confirmatory evidence. This situation is reminiscent of the Catch-22 in autism research and diagnosis in that defining autism as a disease $^{3}$ bars people from positively identifying as autistic and as such from contributing to improved mutual understanding (Bervoets and Hens 2020). Therefore, we propose to listen attentively to the lived experience reports of Tourettic people to gain a - literally - more wholesome view of Tourette's. This is in line with neurodiversity research practices where, led by the case of autism, qualitative research methods take center stage to improve understanding of experiential differences (Hens and Langenberg 2018).

As mentioned above, qualitative research into the lived experience of Tourettic people can clarify how tics follow when one's surroundings feel (not-)just-right (Beljaars forthcoming). Such research emphasizes a relationality of tics which, echoing autobiographical reports, addresses the building up of a swelling sensation (like a tingling or an itch needing to be attended to) screaming for attention to be made 'just-right' again (Bliss 1980, Hollenbeck 2003). In stark contrast to diagnosis and research based on quantifying tic count of mainly stereotypical upper body tics unrelated to environmental circumstances (because needing to be observed in a standardized laboratory or diagnostic condition), the lived experience reports therefore render 'more complex' tics related to the socio-material environment visible again. This repositions 'complex tics', such as ordering, touching or aligning, as crucial to the Tourettic experience. Likewise, it allows to integrate key aspects that are associated with Tourette Syndrome, for instance, the compensatory or masking strategies often conceptualised as 'cognitive tics', such as 'counting tics' (Janik et al. 2021). Moreover, these aspects are crucial in the felt impairment reported by those diagnosed ${ }^{4}$, as they can, for example, tie into compulsions bordering on the obsessive, such as rituals of cleaning or leaving the house (Gagné 2019). Furthermore, such integration may help to put in focus those 'internalized' kinds of tics that are more often performed by non-male Tourettic people (Garcia-Delgar et al. 2021), and it may also shed light on the tic-related clinical issues surging during the COVID-19 pandemic and related to increased social media use (Heyman et al 2021).

\footnotetext{
${ }^{2}$ We choose this word deliberately over 'conceived as' to indicate that the pathological focus on Tourette Syndrome and tics is an active choice rather than a matter of 'merely neutral scientific discovery'.

${ }^{3}$ Unlike autism, a diagnosis of Tourette Syndrome (APA 2013) does not require assessing the individual as being dysfunctional. This provides an opening for considering the problems related to Tourette's as, in a way commensurate with the neurodiversity movement.

${ }^{4}$ It should be noted that this aligns with the abundant empirical evidence on tic quantity measured by accepted tic severity scales diverging drastically from self-reports of felt impairment (Groth et al. 2019).
} 
The production of Tourette Syndrome as a brain disease or deficit - a lack of inhibition - is then simultaneously an erasure of important aspects of the lived experiences of Tourette's and renders its complexity unintelligible. This criticism echoes the new enactive approach to psychiatry, see for instance de Haan (2021). Enactive theory is an empirically inspired approach affiliated with the 4E-trend of Embodied, Enactive, Ecological and Embedded research in cognitive science. For enactive theory, an understanding of phenomena of the mind cannot be reduced to the neurological make-up of an individual but always resides in a relational interplay between the embodied subject and their (non-human and social) environment (Di Paolo et al. 2019). This does not mean neurological differences are not to be investigated, specifically insofar as neurodiversity is investigated. It does mean that, in line with what is said above, the phenomenon of Tourette's cannot be reduced to a brain deficit, but has to be seen as emerging relationally between an individual's sensorimotor atypicality and a social environment that is optimized for typical agents as well as normated towards typical behavior, as has been worked out in the case of autism (Van Es and Bervoets 2021; De Jaegher 2013).

Although it is beyond the scope of the present paper to work out an alternative to the brain deficit view of Tourette Syndrome, it is clear from the above that a 'lack of inhibition' view is largely incompatible with the relationality expressed in Tourettic lived experience. Rather, as already suggested for autism (Bervoets 2021) a 'neurogradualist' approach is needed; one in which sensorimotor sensitivities of Tourettic individuals are different in degree rather than categorically different from a neurotypical person. Suggestions for such an alternative solution can already be found in the current neurocentric literature. In "Controversies Surrounding the Pathophysiology of tics", Singer and Augustine (2019) highlight as one of the key questions for the fields to address: "Are tics due to excess excitation or deficient inhibition?". This suggestion is put even more directly by Beste and Münchau (2018) entitling their paper: "Tics and Tourette Syndrome: Surplus of Action rather than Disorder". The suggestion to be followed up then is that of a 'surplus of sensitivity' to environmental stimuli in Tourette's when compared to a neurotypical norm. This would do away with a categorical division between a pathological 'Tourette Syndrome' and 'healthy' individuals. It would thereby not only avoid the stigma born out of essentializing the psychiatric category (Haslam and Kvaale 2015, Lebowitz and Apelbaum 2019) but also, via a neurogradualist conception, positively contribute to inclusion of neurodiversity (Schomerus et al 2013). First and foremost, however, it would do justice to Tourettic people's efforts of trying to make their difference intelligible based on common human sensitivities, not only those of urges (Bliss 1980) but also autobiographical reports of clearly felt surplus of inhibition (Seligman and Hilkevich 1992).

In line with the motivation behind our argument, we close this section with four quotes from Tourettic people obtained during a participatory research effort ${ }^{5}$. These quotes ${ }^{6}$ illustrate how

\footnotetext{
${ }^{5}$ These interviews were two over Skype and two face-to-face, with written notes taken during interviews that were conducted by the first author. The four interviewees expressed interest in co-creating Tourette Syndrome-related research questions of the first author. For the practice of participatory research, see Fletcher-Watson et al. (2019). Formal ethical approval for the use of these quotes was obtained from the relevant ethical committee (ref: SHW_19_65) and explicit informed consent of each of the interviewees was obtained regarding the quotes themselves as well as the context in which they are placed here.

${ }^{6}$ The interviews were conducted in Dutch and have been translated to English by the first author.
} 
far Quality of Life issues for Tourettic people (Cox et al. 2019) have to do with an ever present pressure to inhibit in view of social reactions and stigma.

"I remember very distinctly that, when I was young, I wanted to go to an ice-skating event. When we got there it was very crowded of course, I was acutely aware that I could not do my arm tic so my hands started tingling of course. I enjoyed the race, I had longed so hard to see it live. The energy in my arms however built and built but I could not release it because that would ruin it for everybody and for myself as well of course. When we got out of the stadium and out of the crowd I could finally 'let it go'. The tics were so violent I fell flat on the floor when we were going to our car. It was a wonderful day." (Lydia)

"Whenever I need to present for an audience I take some time to 'straighten myself out'. I know being nervous to present to strangers brings out my tics but I cannot let them out, certainly not at such a time. I don't want to be seen as the guy that made a great presentation despite his Tourette's or something. That is just the way I see it but if you'd ask what hinders me most about it: well, that I need to spend so much energy in not ticcing, because, you know, it is energy I cannot spend in doing those things I want to do well, like presenting and stuff." (Joseph)

"People rarely notice my tics. I don't want them to. I'll sit on my hands and stiffen up my whole body. Maybe count in my head or something like that. Anything really that diverts energy away from being able to do the tics. My father has it as well. He says I should allow to 'let it go', that it's not healthy 'to keep it in' but I feel responsible not to bother others with it. Sometimes I really get obsessed with my diversion tactics. That can be scary too." (Linda)

"Exams are really hard situations for me because they put me in front of an impossible choice: either to disturb others with my tics or to disturb myself by inhibiting them." (Penny)

\section{Letting Tourette's be}

Listening attentively to the lived experience of Tourette's then leads to a dramatic shift away from the classical 'lack of inhibition' deficit model to reveal a constant pressure to inhibit actions that one feels strongly and spontaneously compelled to do. This shift is reminiscent of the case of autism where the original 'lack of empathy' model has had to be revised under the pressure of autistic lived experience reports (Hens and Langenberg 2018). Neurodiversity scholars argued that this original deficit model constituted, in fact, a 'double empathy problem' (Milton 2012) with onlookers being unable to empathize with autistic ways of being. We suggest that a change of focus towards the Tourettic lived experience is not only ethically necessary but has important theoretical implications. 
Such change of focus is already explored, based on enactive theory, in the case of autism as an exercise in 'letting be' (De Jaegher 2020). Letting be is finding out what something 'is' on its own terms, by neither over- or under-determining it, while sensitively interacting with it. This certainly does not mean withholding treatment, but taking a (literally) more wholesome view of a Tourettic person. Maclaren (2002) exemplifies this view with the relation between a race horse and its trainer. Only seeing a horse for its racing capacities is an overdetermination of it. It will lead to it being overtrained and unable to express itself. But not engaging with its racing capacities is an underdetermination of it, a failure to establish a relationship and therefore also limiting its self-expression. What we propose for Tourette's then is to no longer see it only from a detached onlooker point of view and focus on its pathological tics, but to also become more sensitive - relationally - to the issues Tourettic people experience in their lives. In fact, there seems to be a complicity between the onlooker's focus on tics and the Tourettic person's distress about their tics, as the four quotations at the end of the previous section show. Taking away this single focus, and making the effort to understand Tourette's also from its lived experience, allows the Tourettic person to come to their own senses. In fact, we believe that the overall good prognosis as to felt impairment correlates with finding trusted environments where one is 'let be'.

It is outside of the scope of a single paper to fully develop an alternative view, but we hope to have shown that adopting an attitude of 'letting be' to Tourette's will allow a better understanding of it. Sensitively interacting with Tourette's implies listening attentively to the lived experience of Tourettic people, hence not reducing it to standardized and quantifiable tics immediately jumping out to the onlooker eye. It also does not mean: 'letting a Tourettic person' go in the sense of not caring about the trials and tribulations they face. In order to make new progress for the wellbeing of people with Tourette's, the research method of the social sciences and of the medical humanities will be crucial. This reflects, in our view, the philosophy of clinical practice in which a person rather than a disease is a central concern.

\section{Funding:}

$\mathrm{JB}$ is supported by the NeuroEpigenEthics project that is funded by the European Research Council (ERC) under the European Union's Horizon 2020 research and innovation program (grant agreement No 804881).

DB's work was funded by a Postdoctoral Fellowship by the Economic and Social Research Council (ESRC), UK under grant agreement number ES/T009268/1 and Covid extension grant agreement number EP/520597/1.

\section{References:}

American Psychiatric Association. 2013. "Diagnostic and Statistical Manual of Mental Disorders (DSM-5®)". American Psychiatric Pub.

Bervoets, J. (accepted). 'Neurogradualism. Neurodiversity without categorical difference." Special Issue of InterCultural Philosophy "Temporality, Corporality, 
and Intersubjectivity", Deutsche Gesellschaft für phänomenologische Anthropologie, Psychiatrie und Psychotherapie, Heidelberg.

Bervoets, Jo, and Kristien Hens. (2020). "Going Beyond the Catch-22 of Autism Diagnosis and Research. The Moral Implications of (Not) Asking 'What Is Autism?"' Frontiers in Psychology. https://doi.org/10.3389/fpsyg.2020.529193.

Beljaars Diana, 2020 "Towards Compulsive Geographies" Transactions of the Institute of British Geographers 45 (2): 284-298.

https://doi.org/10.1111/tran.12349.

Beljaars, Diana. Forthcoming. "Compulsive Body Spaces". London and New York: Routledge

Beste, Christian, and Alexander Münchau. 2018. "Tics and Tourette Syndrome Surplus of Actions rather than Disorder?" Movement Disorders: Official Journal of the Movement Disorder Society 33 (2): 238-42.

Tracy Bhikram, Adrian Crawley, Paul Arnold, Elia Abi-Jaoude, Paul Sandor. 2020. "Examining the functional activity of different obsessive-compulsive symptom dimensions in Tourette syndrome" Neurolmage: Clinical, Volume 26, pp. 102-198, ISSN 2213-1582, https://doi.org/10.1016/j.nicl.2020.102198

Bliss, J. 1980. "Sensory experiences of Gilles de la Tourette syndrome". Archives of General Psychiatry 37. pp. 1343-1347.

Cox, J. H., Nahar, A., Termine, C., Agosti, M., Balottin, U., Seri, S., \& Cavanna, A. E. 2019. "Social stigma and self-perception in adolescents with tourette syndrome." Adolescent health, medicine and therapeutics, 10, 75-82. https://doi.org/10.2147/AHMT.S175765

Curtis-Wendlandt, L., Reynolds, J. 2021. "Why Tourette syndrome research needs philosophical phenomenology." Phenom Cogn Sci 20, 573-600. https://doi.org/10.1007/s11097-020-09688-w

De Jaegher, H. (in press). "Seeing and inviting participation in autistic interactions." Transcultural Psychiatry

De Haan, S. 2020. "Enactive Psychiatry." Cambridge: Cambridge University Press. doi:10.1017/9781108685214

Di Paolo, E., Cuffari, E. C., \& De Jaegher, H. 2019. "Linguistic Bodies: The Continuity Between Life and Language." Cambridge, MA, USA: MIT Press.

Eddy, Clare M., and Andrea E. Cavanna. 2013. "On Being Your Own Worst Enemy: An Investigation of Socially Inappropriate Symptoms in Tourette Syndrome." Journal of Psychiatric Research.https://doi.org/10.1016/j.jpsychires.2013.05.019.

Fletcher-Watson, S., Adams, J., Brook, K., Charman, T., Crane, L., Cusack, J., Pellicano, E. 2019. "Making the future together: Shaping autism research through meaningful participation". Autism, 23(4), 943-953. 
Gagné, Jean-Philippe. 2019. "The Psychology of Tourette Disorder: Revisiting the Past and Moving toward a Cognitively-Oriented Future." Clinical Psychology Review 67 (February): 11-21.

Garcia-Delgar B, Servera M, Coffey BJ, Lázaro L, Openneer T, Benaroya-Milshtein N, Steinberg T, Hoekstra PJ, Dietrich A, Morer A; EMTICS collaborative group. 2021. "Tic disorders in children and adolescents: does the clinical presentation differ in males and females? A report by the EMTICS group." Eur Child Adolesc

Psychiatry. 2021 May 4. doi: 10.1007/s00787-021-01751-4. Epub ahead of print. PMID: 33944988.

Groth, Camilla, Liselotte Skov, Theis Lange, and Nanette M. Debes. 2019. "Predictors of the Clinical Course of Tourette Syndrome: A Longitudinal Study." Journal of Child Neurology 34 (14): 913-21.

Haslam, Nick, and Erlend P. Kvaale. 2015. "Biogenetic Explanations of Mental Disorder." Current Directions in Psychological Science.

Hens, K., and Langenberg, R. (2018). Experiences of Adults Following an Autism Diagnosis. Cham: Springer. doi: 10.1007/978-3-319-97973-1

Hollenbeck, P.J. 2003. "A Jangling Journey: Life with Tourette Syndrome”. Cerebrum 5(3), pp. 47-61.

Hyman SE. "Psychiatric Disorders: Grounded in Human Biology but Not Natural Kinds." Perspect Biol Med. 2021;64(1):6-28. doi: 10.1353/pbm.2021.0002. PMID: 33746127.

Heyman I, Liang H, Hedderly T (2021). COVID-19 related increase in childhood tics and tic-like attacksArchives of Disease in Childhood 106: 420-421.

Janik, P., Dunalska, A., Szejko, N., \& Jakubczyk, A. (2021). "Cognitive Tic-Like Phenomena in Gilles de la Tourette Syndrome." Journal of clinical medicine, 10(13), 2749. https://doi.org/10.3390/jcm10132749

Kenny, L., Hattersley, C., Molins, B., Buckley, C., Povey, C., and Pellicano, E. (2016). Which terms should be used to describe autism? Perspectives from the UK Autism Community. Autism 20, 442-462. doi: 10.1177/13623613155 88200

Kim, Soyoung, Deanna J. Greene, Emily C. Bihun, Jonathan M. Koller, Jacqueline M. Hampton, Haley Acevedo, Angela M. Reiersen, Bradley L. Schlaggar, and Kevin J. Black. 2019. "Provisional Tic Disorder Is Not so Transient." Scientific Reports. https://doi.org/10.1038/s41598-019-40133-4.

Kushner, Howard I. 1999. "A Cursing Brain? The Histories of Tourette Syndrome: The Histories of Tourette Syndrome". Harvard University Press.

Lebowitz, Matthew S., and Paul S. Appelbaum. 2019. "Biomedical Explanations of 
Psychopathology and Their Implications for Attitudes and Beliefs About Mental Disorders." Annual Review of Clinical Psychology 15 (May): 555-77.

Leckman J.F., Walker DA, Cohen DJ 1993, "Premonitory urges in Tourette's syndrome". Journal of American Psychiatry 150, pp. 98-102.

Maclaren, K. 2002. Intercorporeality, Intersubjectivity and the Problem of 'Letting Others Be'. Chiasmi International: Trilingual Studies Concerning Merleau-Ponty's Thought, 4, 187-210.

Malli, Melina A., Rachel Forrester-Jones, and Glynis Murphy. 2016. "Stigma in Youth with Tourette's Syndrome: A Systematic Review and Synthesis." European Child \& Adolescent Psychiatry 25 (2): 127-39.

Milton, D. E. M. 2012. "On the ontological status of autism: the 'double empathy problem'." Disability \& Society, 27(6), 883-887.

doi:10.1080/09687599.2012.710008

Pagliaroli, Luca, Borbála Vető, Tamás Arányi, and Csaba Barta. 2016. "From Genetics to Epigenetics: New Perspectives in Tourette Syndrome Research." Frontiers in Neuroscience 10 (July): 277.

Tamara Pringsheim, Michael S. Okun, Kirsten Müller-Vahl, Davide Martino, Joseph Jankovic, Andrea E. Cavanna, Douglas W. Woods, Michael Robinson, Elizabeth Jarvie, Veit Roessner, Maryam Oskoui, Yolanda Holler-Managan, John Piacentini. “

Qi, Yanjie, Yi Zheng, Zhanjiang Li, Zhisheng Liu, and Lan Xiong. 2019. "Genetic Studies of Tic Disorders and Tourette Syndrome." Methods in Molecular Biology 2011: 547-71.

Robertson, Mary May, and Valsamma Eapen. 2014. "Tourette's: Syndrome, Disorder or Spectrum? Classificatory Challenges and an Appraisal of the DSM Criteria." Asian Journal of Psychiatry 11 (October): 106-13.

Schomerus G, Matschinger H, Angermeyer MC. 2013. "Continuum beliefs and stigmatizing attitudes towards persons with schizophrenia, depression and alcohol dependence." Psychiatry Res. 2013 Oct 30;209(3):665-9. doi: 10.1016/j.psychres.2013.02.006. Epub 2013 Mar 5. PMID: 23465293.

Schroeder, Timothy. 2005. "Moral Responsibility and Tourette Syndrome." Philosophy and Phenomenological Research. https://doi.org/10.1111/j.1933-1592.2005.tb00432.x.

Seligman, Adam Ward, and John S. Hilkevich. 1992. "Don't Think about Monkeys: Extraordinary Stories by People with Tourette Syndrome." Hope Press.

Silva, R. R., Munoz, D. M., Barickman, J., \& Friedhoff, A. J. (1995). Environmental factors and related fluctuation of symptoms in children and adolescents with Tourette's disorder. Child Psychology \& Psychiatry \& Allied Disciplines, 36(2), 
305-312. https://doi.org/10.1111/j.1469-7610.1995.tb01826.x

Singer, Harvey S., and Farhan Augustine. 2019. "Controversies Surrounding the Pathophysiology of Tics." Journal of Child Neurology 34 (13): 851-62.

Specht MW, Woods DW, Nicotra CM, Kelly LM, Ricketts EJ, Conelea CA, Grados MA, Ostrander RS, Walkup JT. (2013). "Effects of tic suppression: ability to suppress, rebound, negative reinforcement, and habituation to the premonitory urge". Behaviour Research and Therapy, 51(1):24-30.

Strawson, P. F. 2008. "Freedom and Resentment and Other Essays." Routledge. https://doi.org/10.4324/9780203882566.

van Es, T., Bervoets, J. (Accepted) "Autism as gradual sensorimotor difference: From enactivism to ethical inclusion." Topoi. 